\title{
Complexation of Uranyl Ion with Sulfonates: One- to Three-Dimensional Assemblies with 1,5- and 2,7-Naphthalenedisulfonates
}

\author{
Pierre Thuéry, ${ }^{*,[a]}$ and Jack Harrowfield*,[b] \\ [a] NIMBE, CEA, CNRS, Université Paris-Saclay, CEA Saclay, 91191 Gif-sur-Yvette, France \\ E-mail: pierre.thuery@cea.fr \\ http://iramis.cea.fr/nimbe/ \\ ${ }^{[b]}$ ISIS, Université de Strasbourg, 8 allée Gaspard Monge, 67083 Strasbourg, France \\ E-mail: harrowfield@unistra.fr \\ https://isis.unistra.fr/
}

Keywords: Uranium(VI) / Sulfonic acids / Cucurbiturils / Structure elucidation / Metal-organic frameworks

\begin{abstract}
Uranyl nitrate was reacted with the sodium salt of either 1,5- or 2,7-naphthalenedisulfonate (1,5$\mathrm{ndsNa}_{2}$ and 2,7-ndsNa $\mathrm{Na}_{2}$, respectively) under (solvo)-hydrothermal conditions, in the presence of additional coligands and/or metal cations, to give six new complexes which were characterized by their crystal structure determinations. $\left[\mathrm{UO}_{2}(1,5-\mathrm{nds})\left(\mathrm{H}_{2} \mathrm{O}\right)\right](\mathbf{1})$ crystallizes as a three-dimensional (3D) framework, with both sulfonate groups coordinated in the $O, O^{\prime}$-bridging mode. In the presence of the $N$-chelating species 2,2'-bipyridine (bipy) or 1,10-phenanthroline (phen), the three complexes $\left[\left(\mathrm{UO}_{2}\right)_{2}(1,5-\right.$ nds $\left.)(\mathrm{OH})_{2}(\text { bipy })_{2}\right] \cdot \mathrm{H}_{2} \mathrm{O}(\mathbf{2}),\left[\left(\mathrm{UO}_{2}\right)_{2}(1,5\right.$-nds $\left.)(\mathrm{OH})_{2}(\text { bipy })_{2}\right] \cdot$ bipy $(3)$ and $\left[\left(\mathrm{UO}_{2}\right)_{2}(1,5-\right.$ nds $\left.)(\mathrm{OH})_{2}(\text { phen })_{2}\right]$ (4) were obtained, in which doubly hydroxide-bridged uranyl dimers are assembled into one-dimensional (1D) chains by bis(unidentate) disulfonate ligands. The complex $\left[\mathrm{Cu}(\text { bipy })_{2} \mathrm{Cl}\right]\left[\mathrm{UO}_{2}(2,7-\right.$ nds $\left.)(\mathrm{OH})\right] \cdot \mathrm{H}_{2} \mathrm{O}$ (5) displays anionic, two-dimensional (2D) sheets in which unidentate $O, O^{\prime}$-bridging disulfonate ligands link hydroxide-bridged uranyl dimers. In the additional presence of cucurbit[6]uril (CB6), the complex $\left[\left(\mathrm{UO}_{2}\right)_{4} \mathrm{Na}_{4}(2,7-\mathrm{nds})_{2}(\mathrm{CB} 6) \mathrm{Cl}_{4} \mathrm{O}_{2}\left(\mathrm{H}_{2} \mathrm{O}\right)_{10}\right] \cdot 5 \mathrm{H}_{2} \mathrm{O}(6)$ crystallizes as a 3D framework of intricate architecture, with bis( $\mu_{3}$-oxo) bridged uranyl tetranuclear moieties connected to CB6-bound sodium cations by doubly $O, O^{\prime}$-bridging disulfonates. Complexes $\mathbf{2}$ and $\mathbf{4}$ display intense and well-resolved uranyl emission in the solid state, while nearly complete quenching is observed in $\mathbf{3}$ and $\mathbf{5}$.
\end{abstract}




\section{Introduction}

Although considered as a relatively weak O-donor entity, one reason the sulfonate group has been widely investigated is precisely because this characteristic renders it of potential interest for the construction of flexible coordination networks. ${ }^{[1-4]}$ Aromatic sulfonates, which occupy an intermediate range of the donor strength of known systems, ${ }^{[5]}$ have been a particular focus in the form of divergently-substituted polysulfonates which can give rise to "pillared" layer structures in their metal ion complexes ${ }^{[1-4]}$ analogous to those seen in hydrogen bonded systems such as guanidinium organosulfonates. ${ }^{[6]}$ As a donor group, $\mathrm{RSO}_{3}{ }^{-}$is most commonly found in unidentate or $O, O^{\prime}$-bridging modes, with $O, O^{\prime}$-chelation (and, rarely, tripodal-bridging coordination) only being found, as might be expected, with larger metal ions. ${ }^{[1-4]}$ Although aromatic sulfonates do not appear to be particularly good ligands for the lighter lanthanide(III) ions, ${ }^{[7]}$ it is significant that in mixed $\mathrm{Ln} /$ uranyl ion $(\mathrm{Ln}=\mathrm{Ce}, \mathrm{Eu})$ complexes of $p$-sulfonatocalix[4]arene, ${ }^{[8]}$ the uranyl ions do form in part $O, O^{\prime}$-chelate rings with sulfonate while the $\operatorname{Ln}($ III) ions show only unidentate coordination, indicating potential utility of sulfonates in actinide/lanthanide separation. While larger sulfonated calixarenes are considered to be "uranophiles", ${ }^{[9-11]}$ there is no structural information on the complexes involved or certainty as to how or even if the sulfonate groups coordinate to $\mathrm{U}^{\mathrm{VI}}$. The aliphatic ethane-1,2-disulfonate gives crystalline uranyl ion complexes in which it is either doubly unidentate ${ }^{[12,13]}$ or $O, O^{\prime}$-bridging bidentate, ${ }^{[14]}$ the latter coordination mode being seemingly preferred for methane- and ethanesulfonates, ${ }^{[15-18]}$ although tripodal $O, O^{\prime}, O^{\prime \prime}-$ coordination is also known in the former case. ${ }^{[18]}$ In contrast, the common trifluoromethanesulfonate anion is unidentate in all its uranyl complexes reported in the Cambridge

Structural Database (CSD, Version 5.37). ${ }^{[19]}$ The aromatic monosulfonates, 4-methylbenzene (toluene) sulfonate and 2,4,6-trimethyl (mesityl) sulfonate, behave as unidentate donors to uranyl 
ion, ${ }^{[16,20]}$ but it was recently found that the former could also act as an $O, O^{\prime}$-bridging ligand. ${ }^{[21]}$ Various aromatic monosulfonates with additional carboxylate or hydroxyl coordinating groups also display unidentate sulfonate coordination (as part of a chelate ring), although $O, O^{\prime}$-bridging is also observed in some cases. ${ }^{[13,14,22-26]}$ Bridging of uranyl centers by disulfonate or mixed hydroxyl- or carboxylate-sulfonate ligands is propitious for the formation of uranyl-organic coordination polymers or frameworks (UOFs), ${ }^{[27-29]}$ a domain in which they are much less investigated than phosphonates. ${ }^{[26]}$ Among the examples of such compounds previously reported, several include cucurbit[6]uril (CB6) as coligands or templating species, ${ }^{[12,14,22]}$ thus giving architectures that are often quite intricate, as well as, in some cases, enabling isolation of uranyl complexes with sulfonate ligands that resist crystallization in the absence of CB6. ${ }^{[14,22]}$ This interest of sulfonates for the building of UOFs, coupled with the somewhat uncertain overall view of sulfonate binding to uranyl ion led to our present efforts to characterise the situation in crystalline uranyl ion complexes of aromatic disulfonates, namely 1,5- and 2,7-naphthalenedisulfonates (1,5- and 2,7nds $^{2-}$ ), capable of bridging, but not chelation through both sulfonate groups. In extension of recent work, of particular interest was how uranyl-sulfonate coordination might be influenced by the presence of other metal ions, so that our initial experiments were directed towards the possible synthesis of mixed-metal species, although success was limited in this regard. The crystal structures of six complexes obtained in the course of this work, one of them including CB6 molecules, with dimensionalities ranging from one to three, are reported herein, as well as, in most cases, their emission spectrum in the solid state at room temperature. 


\section{Results and Discussion}

\section{Crystal Structures}

The complex $\left[\mathrm{UO}_{2}(1,5-\mathrm{nds})\left(\mathrm{H}_{2} \mathrm{O}\right)\right]$ (1) crystallizes in the orthorhombic space group Pbcn, with the uranium atom located on a two-fold rotation axis (Wyckoff position 4c) and the disulfonate ligand being centrosymmetric (Figure 1). The uranyl group is bound to four sulfonate oxygen atoms pertaining to four different anions [U-O bond lengths 2.403(2) and 2.428(2) $\AA$; the average value
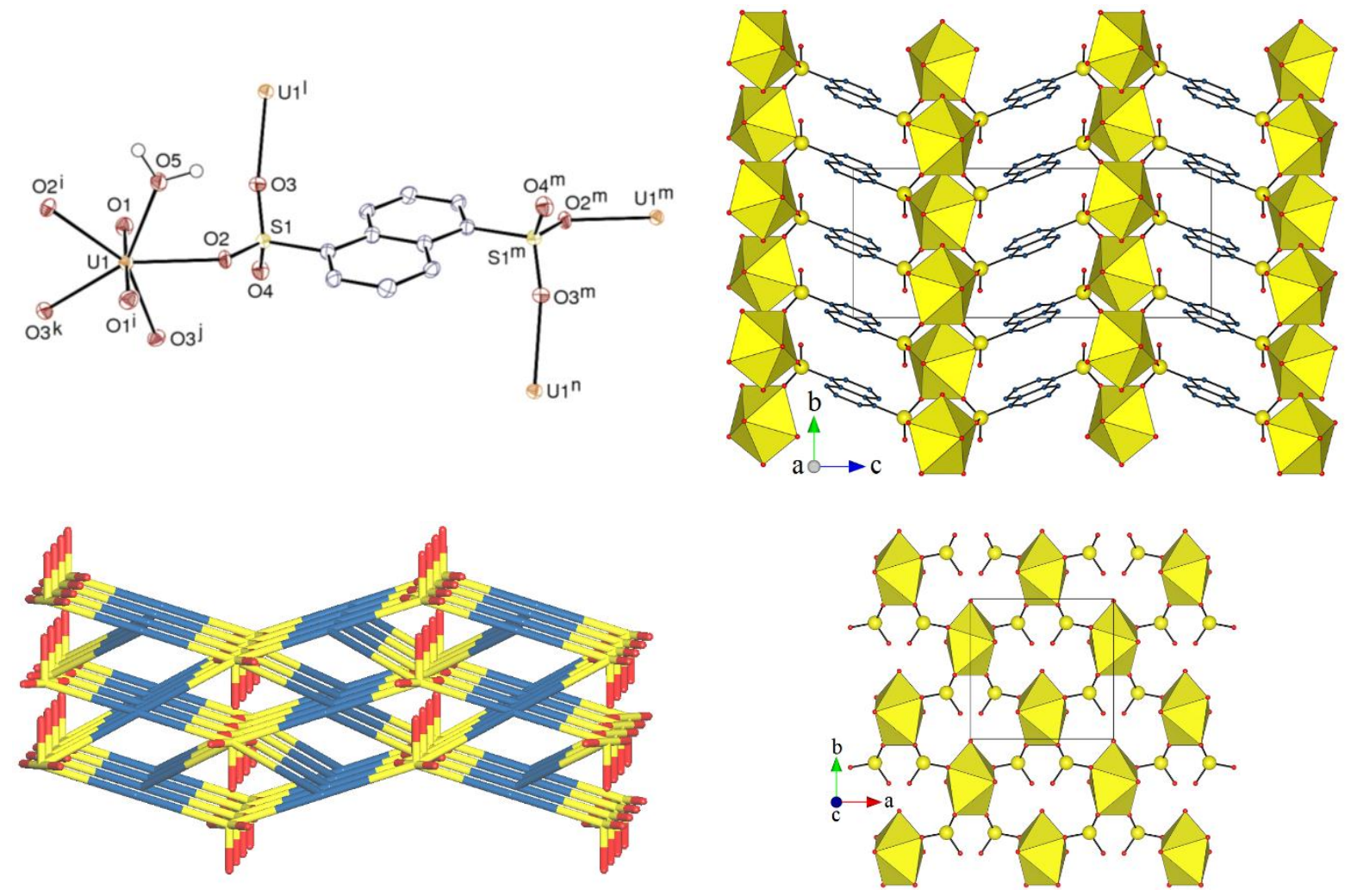

Figure 1. Top left: View of complex 1. Displacement ellipsoids are drawn at the 50\% probability level. The carbon-bound hydrogen atoms are omitted. Symmetry codes: $\mathrm{i}=1-x, y, 1 / 2-z ; \mathrm{j}=3 / 2-x, y-1 / 2, z ; \mathrm{k}=x-1 / 2, y-1 / 2,1 / 2-z ; 1=x$ $+1 / 2, y+1 / 2,1 / 2-z ; \mathrm{m}=2-x, 1-y, 1-z ; \mathrm{n}=3 / 2-x, 1 / 2-y, z+1 / 2$. Top right: View of the 3D framework with uranium coordination polyhedra colored yellow. Bottom left: Nodal representation of the framework down an axis slightly inclined from that in the previous view (yellow: uranium, red: oxygen, blue: disulfonate ligand). Bottom right: View of the 2D subunit with only one $\mathrm{SO}_{3}{ }^{-}$group shown for each ligand. 
for structures reported in the CSD is 2.40(4) $\AA$ ] and to one water molecule located on the two-fold rotation axis [U1-O5 2.375(4) $\AA$ ]. The uranium atom environment is thus pentagonal bipyramidal. The disulfonate ligand is doubly $O, O^{\prime}$-bridging $\left(\operatorname{bis}\left(\mu_{2}-\eta^{1}: \eta^{1}\right)\right.$ coordination mode) and thus bound to four metal cations. The assembly formed is three-dimensional (3D), with the point (Schläfli) symbol $\left\{6^{5} .10\right\}\left\{6^{5} .8\right\}$ (symbols for ligand and uranium four-fold nodes, respectively), and views of the lattice and its nodal representation are shown in Figure 1. The framework has a layered appearance and the naphthalene units can be considered as "pillars" linking two-dimensional (2D) polymeric sheets parallel to $\left(\begin{array}{lll}0 & 0 & 1\end{array}\right)$, in which connection of $\mathrm{UO}_{2}\left(\mathrm{O}_{2} \mathrm{SO}\right)_{4}\left(\mathrm{H}_{2} \mathrm{O}\right)$ units generates an array of fused 16-membered rings; this 2D array has the topology of a square grid with four-fold uranium nodes and the sulfonate groups being simple links (Figure 1). The uranyl oxo atom O1 is at $3.09 \AA$ from one naphthalene carbon atom, and at $2.80 \AA$ from the corresponding hydrogen atom, a weak interaction which is apparent in the Hirshfeld surface ${ }^{[30]}$ obtained using CrystalExplorer. ${ }^{[31]}$ The coordinated water molecule is hydrogen bonded to the uncoordinated sulfonate atom $\mathrm{O} 4$ $\left[\mathrm{O} 5 \cdots \mathrm{O} 4^{\mathrm{ii}} 2.669(3) \AA, \mathrm{H} \cdots \mathrm{O} 4^{\mathrm{ii}} 1.74 \AA, \mathrm{O} 5-\mathrm{H} \cdots \mathrm{O} 4^{\mathrm{ii}} 164^{\circ}\right.$; symmetry code $\mathrm{ii}=x-1 / 2, y+1 / 2,1 / 2$ $-z]$ and its image by the rotation axis, which is also apparent from the Hirshfeld surface, as well as a further interaction of $\mathrm{O} 4$ with one naphthalene hydrogen atom $(2.51 \AA)$. Within the organic layer, the shortest contacts between centroids of aromatic rings are at $4.4 \AA$ (the corresponding dihedral angle being $23^{\circ}$ ), and analysis of the Hirshfeld surfaces confirms that there is no evidence of significant $\pi$-stacking of the aromatic planes. The Kitaigorodski packing index (KPI, estimated with PLATON ${ }^{[32]}$ ) of 0.76 is indicative of a compact packing with no significant free space left.

The three complexes $\left[\left(\mathrm{UO}_{2}\right)_{2}(1,5-\mathrm{nds})(\mathrm{OH})_{2}(\text { bipy })_{2}\right] \cdot \mathrm{H}_{2} \mathrm{O} \quad(\mathbf{2}), \quad\left[\left(\mathrm{UO}_{2}\right)_{2}(1,5-\right.$ nds $\left.)(\mathrm{OH})_{2}(\text { bipy })_{2}\right] \cdot$ bipy $(3)$ and $\left[\left(\mathrm{UO}_{2}\right)_{2}(1,5-\mathrm{nds})(\mathrm{OH})_{2}(\text { phen })_{2}\right](\mathbf{4})$ all contain an additional chelating $N$-donor, either 2,2'-bipyridine (bipy) or 1,10-phenanthroline (phen), as well as hydroxide ions. The 
consequences of the presence of these $N$-donors (and also that of $\mathrm{Mn}^{\mathrm{II}}, \mathrm{Ni}^{\mathrm{II}}$ or $\mathrm{Pb}^{\mathrm{II}}$, although they are not present in the final compounds) instead of 18-crown-6 in the reaction mixture proved to be quite dramatic in several ways, although the yield of crystallization of these three compounds remains low, possibly indicating that again a rather complicated mixture was present in the solution phase. The presence of the hydroxo ligands is presumably a reflection of the higher $p \mathrm{H}$ of the reaction mixture due to the addition of bipy or phen. The asymmetric unit contains either two uranium atoms (2) or only one (3 and 4); views of the three complexes are shown in Figures 2-4, respectively. In all three


Figure 2. Top: View of complex 2. Displacement ellipsoids are drawn at the $50 \%$ probability level. The solvent molecule and carbon-bound hydrogen atoms are omitted. Symmetry codes: $\mathrm{i}=2-x, 1-y, 1-z ; \mathrm{j}=-x, 1-y, 2-z$. Bottom: Packing of the 1D polymeric chains. 

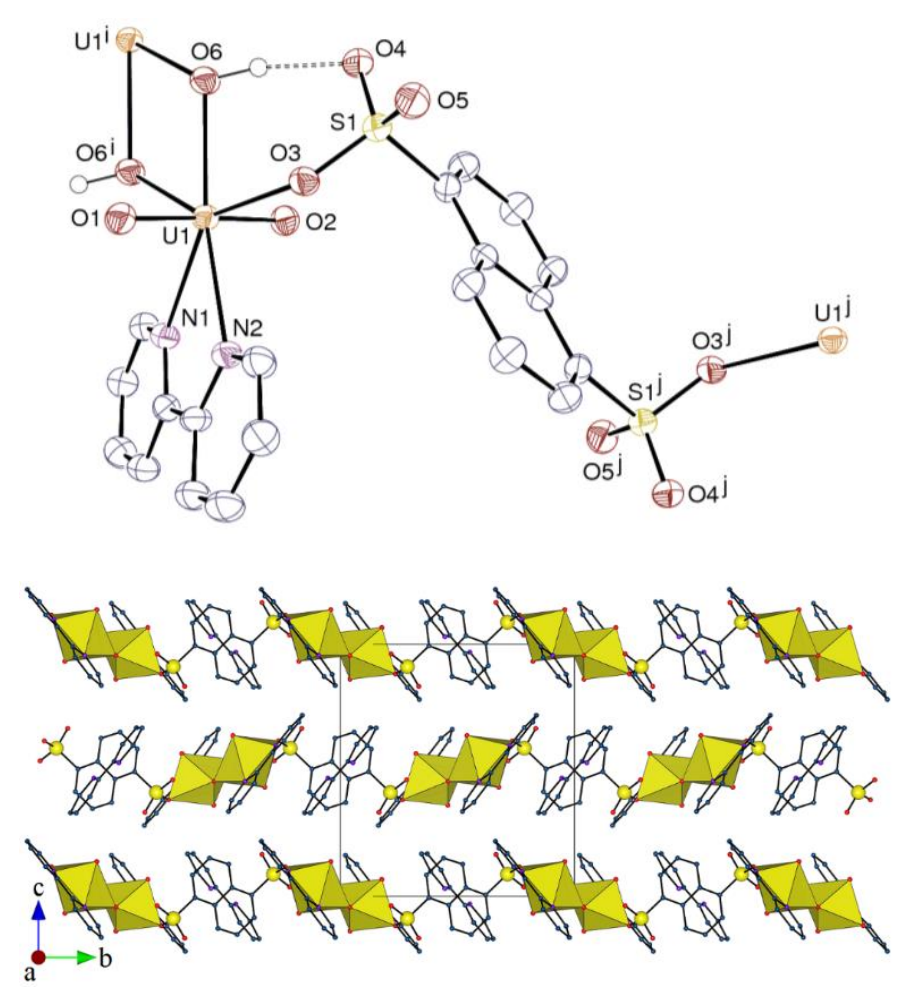

Figure 3. Top: View of complex 3. Displacement ellipsoids are drawn at the $50 \%$ probability level. The free bipy molecule and carbon-bound hydrogen atoms are omitted. The hydrogen bond is shown as a dashed line. Symmetry codes: $\mathrm{i}=1-x, 1-y, 1-z ; \mathrm{j}=1-x, 2-y, 1-z$. Bottom: Packing of the 1D polymeric chains.

cases, the uranium atom is chelated by one $N$-donor [U-N bond lengths in the range 2.578(3)2.633(4) $\AA$, average 2.60(2) $\AA$; the average value for structures reported in the CSD is 2.62(4) $\AA$ ]. Two bridging $\mu_{2}-\eta^{1}: \eta^{1}$ hydroxide ions (related to one another by an inversion centre in $\mathbf{3}$ and $\mathbf{4}$ ) and one sulfonate oxygen atom complete the pentagonal equatorial uranyl environment. The UO(hydroxide) bond lengths are in the range 2.280(2)-2.361(3) $\AA$ [average 2.32(3) $\AA$ ] and the U-O$\mathrm{U}$ angles are in the range $110.04(15)-112.06(14)^{\circ}$ [average $111.1(7)^{\circ}$ ]; these values are in good agreement with those for the 28 similar uranyl dimers with double hydroxide bridges reported in the CSD, that are in the ranges $2.28-2.37 \AA$ [average $2.33(2) \AA$ ] and $106.7-116.8^{\circ}$ [average $112(2)^{\circ}$ ]. 

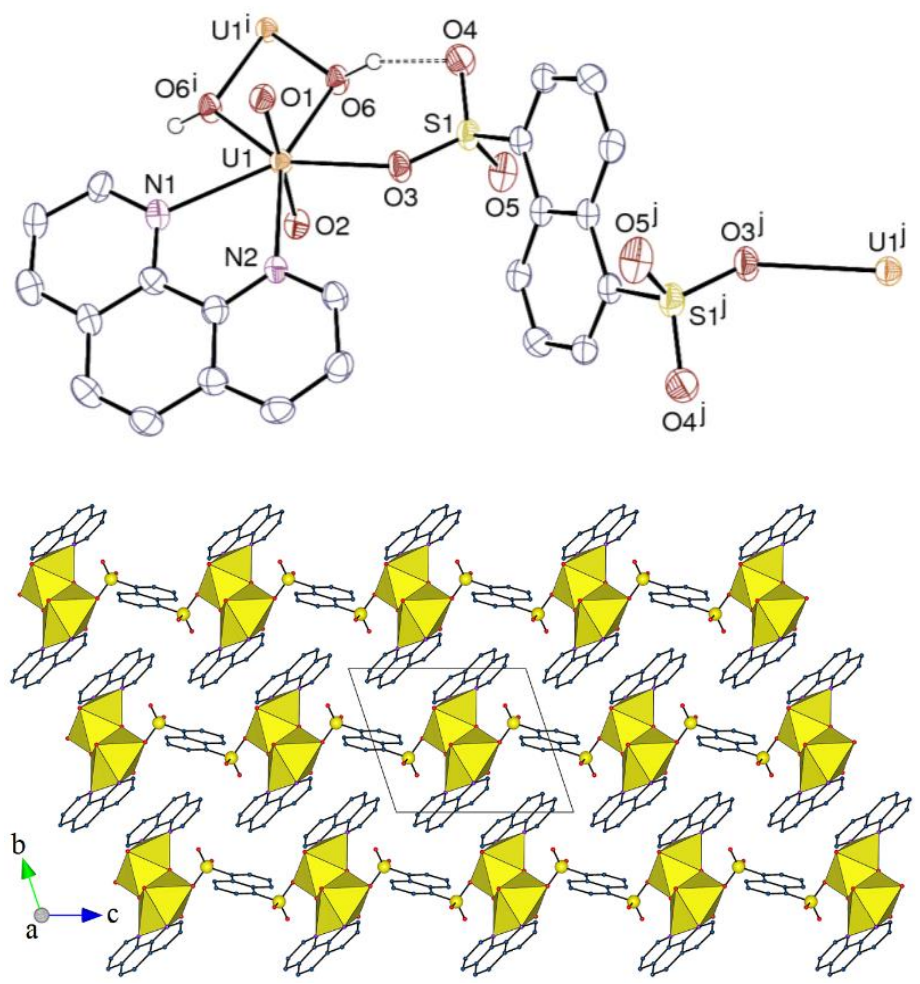

Figure 4. Top: View of complex 4 . Displacement ellipsoids are drawn at the $50 \%$ probability level. The carbon-bound hydrogen atoms are omitted and the hydrogen bond is shown as a dashed line. Symmetry codes: $\mathrm{i}=-x, 1-y, 1-z ; \mathrm{j}$ $=1-x, 1-y,-z$. Bottom: Packing of the 1D polymeric chains.

The U-O(sulfonate) bond lengths are in the range 2.385(4)-2.424(2) $\AA$ [average 2.409(15) $\AA$ ] and they are thus close to those in complex $\mathbf{1}$. As always in uranyl complexes including chelating bipy or phen molecules, or their derivatives, the equatorial environment is far from planar, the two nitrogen donors being displaced out of the plane defined by the other donors, the latter plane being approximately perpendicular to the uranyl axis, thus inducing chirality at the uranium centre. ${ }^{[33]} \mathrm{In}$ the present cases, the out-of-plane displacements of nitrogen atoms are in the range 0.119(9)$0.592(5) \AA$, being most reduced in the phen-containing complex 4, and the dihedral angles between the bipy or phen average plane and the mean plane defined by uranium and the three oxygen donors are $19.40(9) / 15.69(12), 23.78(7)$ and $19.08(17)^{\circ}$ in $\mathbf{2}-\mathbf{4}$, respectively. The latter values are smaller 
than those observed in more crowded eight-coordinate complexes, in which dihedral angles of more than $40^{\circ}$ have been measured, but it is notable that, both in seven- and eight-coordinate complexes, the tilting of phen is generally smaller than that of bipy. ${ }^{[33]}$ In all three compounds, hydroxide bridging gives rise to uranyl dimers (centrosymmetric in $\mathbf{3}$ and $\mathbf{4}$ ) and further bridging by centrosymmetric sulfonate ligands produces one-dimensional (1D) heterochiral polymers directed along the [2 $0-1]$, [ $\left.\begin{array}{lll}0 & 1 & 0\end{array}\right]$ or $\left[\begin{array}{lll}1 & 0 & -1\end{array}\right]$ axes in $\mathbf{2 - 4}$, respectively. While all $1,5-$ nds $^{2-}$ ligands in one chain are parallel to one another in $\mathbf{3}$ and $\mathbf{4}$, two different orientations are present in $\mathbf{2}$. In complexes 2 and $\mathbf{4}$, the chains are arranged side-by-side to form sheets parallel to $\left(\begin{array}{lll}0 & 1 & 0\end{array}\right)$, with the bipy or phen molecules pointing outward on the two faces of the layers, so that inter-sheet contacts possibly associated with parallel-displaced $\pi$-stacking interactions between bipy or phen molecules are present [centroid $\cdots$ centroid distances 3.653(3)-4.293(3) $\AA$, dihedral angles $0-9.1(3)^{\circ}$ in $2 ; 3.845(3)$ and 3.998(3) $\AA, 0$ and 2.4(3) in 4]. A weaker, intra-chain $\pi$-stacking interaction between bipy and

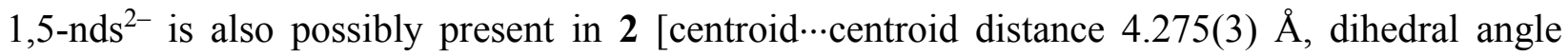
22.6(3) $)^{\circ}$. However, consideration of the Hirshfeld surfaces shows that only the two shortest of these contacts in $\mathbf{2}$, and none in $\mathbf{4}$, reveal interactions beyond dispersion. The presence of a free bipy molecule in complex $\mathbf{3}$, reflecting the higher concentration of bipy in the reaction mixture, modifies this arrangement so that both coordinated and free bipy molecules are located within the sheets parallel to $\left(\begin{array}{lll}0 & 0 & 1\end{array}\right)$. Intra-sheet parallel-displaced $\pi$-stacking interactions involving either two coordinated bipy molecules pertaining to adjacent chains, or coordinated and free moieties may be present [centroid $\cdots$ centroid distances 3.5853(19) and 3.969(2) $\AA$, dihedral angles 0 and $8.26(19)^{\circ}$ ], but examination of the Hirshfeld surfaces indicates that, in this case also, they are no greater than dispersion. Hydroxide ions are involved in hydrogen bonds with the solvent water molecule in $\mathbf{2}$, and with uncoordinated sulfonate oxygen atoms pertaining to the same chain in $\mathbf{3}$ and $\mathbf{4}[\mathrm{O} \cdots \mathrm{O}$ 
distances $2.632(5)-2.832(5) \AA, \mathrm{O}-\mathrm{H} \cdots \mathrm{O}$ angles $\left.158-170^{\circ}\right]$, and the water molecule in 2 forms a hydrogen bond with two sulfonate groups $[\mathrm{O} \cdots \mathrm{O}$ distances $2.788(5)$ and $2.914(5) \AA$, $\mathrm{O}-\mathrm{H} \cdots \mathrm{O}$ angles 171 and $149^{\circ}$ ], thus bridging adjacent chains in the sheets. The presence of uncoordinated sulfonate oxygen atoms not involved in $\mathrm{OH} \cdots \mathrm{O}$ hydrogen bonding in all three compounds results in the formation of weak $\mathrm{CH} \cdots \mathrm{O}$ hydrogen bonds,${ }^{[34,35]}$ with $\mathrm{H} \cdots \mathrm{O}$ distances as short as $2.26 \AA$, which are either intra- or inter-sheet. The packings are slightly more compact in 2 and 4 (KPI 0.73) than in $3(0.70)$, which is probably related to the extra bipy molecule in the latter compound and the ensuing different sheet arrangement.

The complex $\left[\mathrm{Cu}(\text { bipy })_{2} \mathrm{Cl}\right]\left[\mathrm{UO}_{2}(2,7-\mathrm{nds})(\mathrm{OH})\right] \cdot \mathrm{H}_{2} \mathrm{O}(\mathbf{5})$ involves a positional isomer of the ligand different from that in complexes 1-4. In this case, the additional metal cation present in the reaction mixture is incorporated as a counter-ion in the final compound. The unique uranium atom, in a pentagonal bipyramidal environment, is bound to two bridging hydroxide ions, as in complexes 2-4, giving a centrosymmetric dimeric unit [U-O bond lengths $2.310(2)$ and $2.331(2) \AA$, $\mathrm{U}-\mathrm{O}-\mathrm{U}$ angle 113.04(8)], and to three sulfonate oxygen atoms pertaining to three different ligands [U-O bond lengths 2.384(2)-2.4636(19) $\AA$ ] (Figure 5). The 2,7-nds ${ }^{2-}$ ligand is thus bound to three metal cations, one of the sulfonate groups being $O, O^{\prime}$-bridging bidentate and the other unidentate. The peculiarity of the counter-ion is its inclusion of a chloride anion which must have arisen from an impurity in one reagent; since chloride anions were also found in complex $\mathbf{6}$ (see below), it is most probable that they were present in the sample of 2,7-ndsNa2 used. The $\left[\mathrm{Cu}(\text { bipy })_{2} \mathrm{Cl}\right]^{+}$species is however a common one, with 30 examples reported in the CSD. The coordination polymer formed is $2 \mathrm{D}$ and parallel to $\left(\begin{array}{lll}0 & 0\end{array}\right)$, and, if the double hydroxide bridge is considered as a single link, the uranium atoms are four-fold nodes and the 2,7-nds ${ }^{2-}$ ligands three-fold ones. The point symbol, $\left\{4^{2} .6^{3} .8\right\}\left\{4^{2} .6\right\}$ is characteristic of the $\mathrm{V}_{2} \mathrm{O}_{5}$ topological type. Alternatively, if the uranyl dimers 

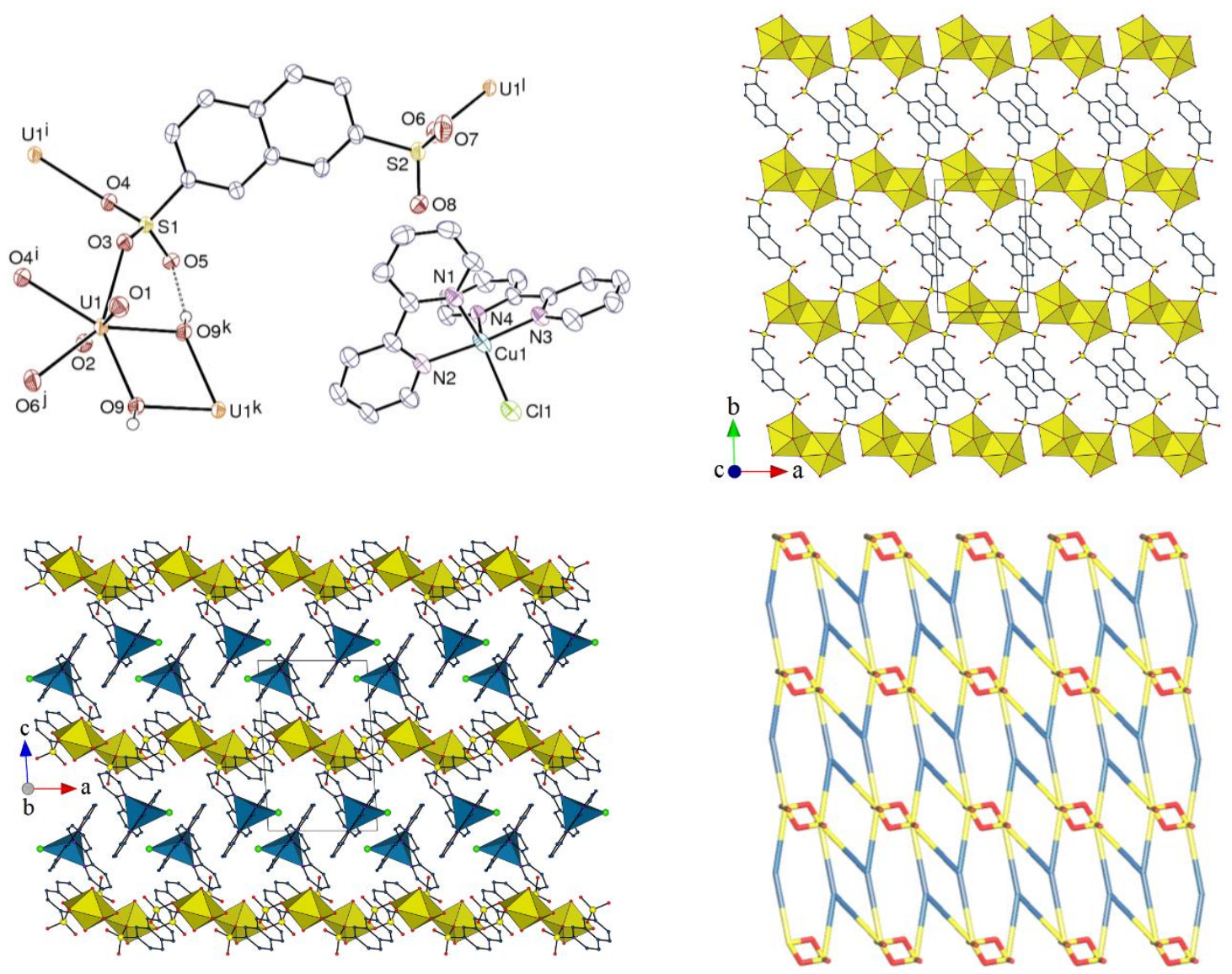

Figure 5. Top left: View of complex 5. Displacement ellipsoids are drawn at the 50\% probability level. The solvent molecule and carbon-bound hydrogen atoms are omitted, and the hydrogen bond is shown as a dashed line. Symmetry codes: $\mathrm{i}=2-x,-y, 1-z ; \mathrm{j}=x, y-1, z ; \mathrm{k}=1-x,-y, 1-z ; 1=x, y+1, z$. Top right: View of the 2D assembly. Bottom left: View of the packing with layers viewed edge-on. Uranyl coordination polyhedra are yellow and those of copper(II) blue. Bottom right: Nodal representation of the 2D assembly (yellow: uranium, red: oxygen, blue: disulfonate ligand).

are considered as single, six-fold nodes, the topology is of the kagome-dual (kgd) type, with the point symbol $\left\{4^{3}\right\}_{2}\left\{4^{6} \cdot 6^{6} \cdot 8^{3}\right\}$. The wide inter-layer spaces (with a distance of $14 \AA$ between the mean planes of the sheets) accommodate the counter-ions, the KPI being 0.70. Several short contacts indicate the possible presence of parallel-displaced $\pi$-stacking interactions between 2,7 nds $^{2-}$ ligands facing each other within the layers [centroid $\cdots$ centroid distance 3.6729(16) $\AA$, dihedral angle $2.98(13)^{\circ}$ ], between the sulfonate ligand and bipy molecules [3.7370(19) and 
$3.7620(18) \AA, 8.57(15)$ and $\left.7.05(15)^{\circ}\right]$, and between bipy molecules [3.972(2) and 4.112(2) $\AA$, 2.24(19) and $\left.0^{\circ}\right]$. However, such interactions in an ionic species represent at most very minor contributions to the cohesion of the packing, which is predominantly the result of electrostatic interactions. ${ }^{[36]}$ The hydroxide anion and the free water molecule are hydrogen bonded to uncoordinated sulfonate oxygen atoms $[\mathrm{O} \cdots \mathrm{O}$ distances 2.842(3)-2.994(4) $\AA, \mathrm{O}-\mathrm{H} \cdots \mathrm{O}$ angles 150 $\left.169^{\circ}\right]$. As in the previous cases, some weak $\mathrm{CH} \cdots \mathrm{O}$ (sulfonate) hydrogen bonding interactions may be present as well.

The last complex, $\left[\left(\mathrm{UO}_{2}\right)_{4} \mathrm{Na}_{4}(2,7-\mathrm{nds})_{2}(\mathrm{CB} 6) \mathrm{Cl}_{4} \mathrm{O}_{2}\left(\mathrm{H}_{2} \mathrm{O}\right)_{10}\right] \cdot 5 \mathrm{H}_{2} \mathrm{O}$ (6), also involves the 2,7-nds ${ }^{2-}$ ligand, as well as cucurbit[6]uril (CB6) as coligand. This is the only complex in the present series to include $\mathrm{Na}^{+}$cations, which are retained through complexation to CB6. As in complex $\mathbf{5}$, chloride anions were probably introduced in the reaction mixture as impurities in the 2,7-ndsNa 2 sample. The asymmetric unit contains two independent uranyl ions which give rise to a bis( $\mu_{3}$-oxo)-bridged tetranuclear species with two-fold rotation symmetry (Figure 6). Atom U1 is bound to one bridging oxo, one sulfonate and two $\mu_{2}$-bridging chloride anions, and to a water molecule, while atom U2 is bound to two bridging oxo and two chloride anions and a water molecule, both being thus in pentagonal bipyramidal environments. The resulting $\left(\mathrm{UO}_{2}\right)_{4} \mathrm{Cl}_{4} \mathrm{O}_{2}$ moiety has previously been described, ${ }^{[37-39]}$ one example including uncoordinated CB6 molecules, ${ }^{[38]}$ and it is a particular case of the common $\left(\mathrm{UO}_{2}\right)_{4} \mathrm{O}_{2}{ }^{4+}$ motif, with diverse additional lateral donors, which has previously been obtained in particular with 2 -sulfobenzoate ${ }^{[13]}$ and $\mathrm{CB} 66^{[40]}$ as co-ligands. The $\mathrm{U}-\mathrm{O}\left(\mu_{3}-\mathrm{oxo}\right)$ bond lengths in $\mathbf{6}$ are in the range 2.207(4)-2.300(4) $\AA$ [average 2.26(4) $\AA$ ] and the three $\mathrm{U}-\mathrm{O}-\mathrm{U}$ angles around this anion sum to $359.84^{\circ}$, indicating a nearly perfect planar geometry. The U-Cl bond lengths [2.7989(19)-2.8718(19) Å, average 2.83(3) $\AA]$ and $\mathrm{U}-\mathrm{Cl}-\mathrm{U}$ angles $\left[89.99(5)\right.$ and $\left.89.40(5)^{\circ}\right]$ are in agreement with the averages from the 

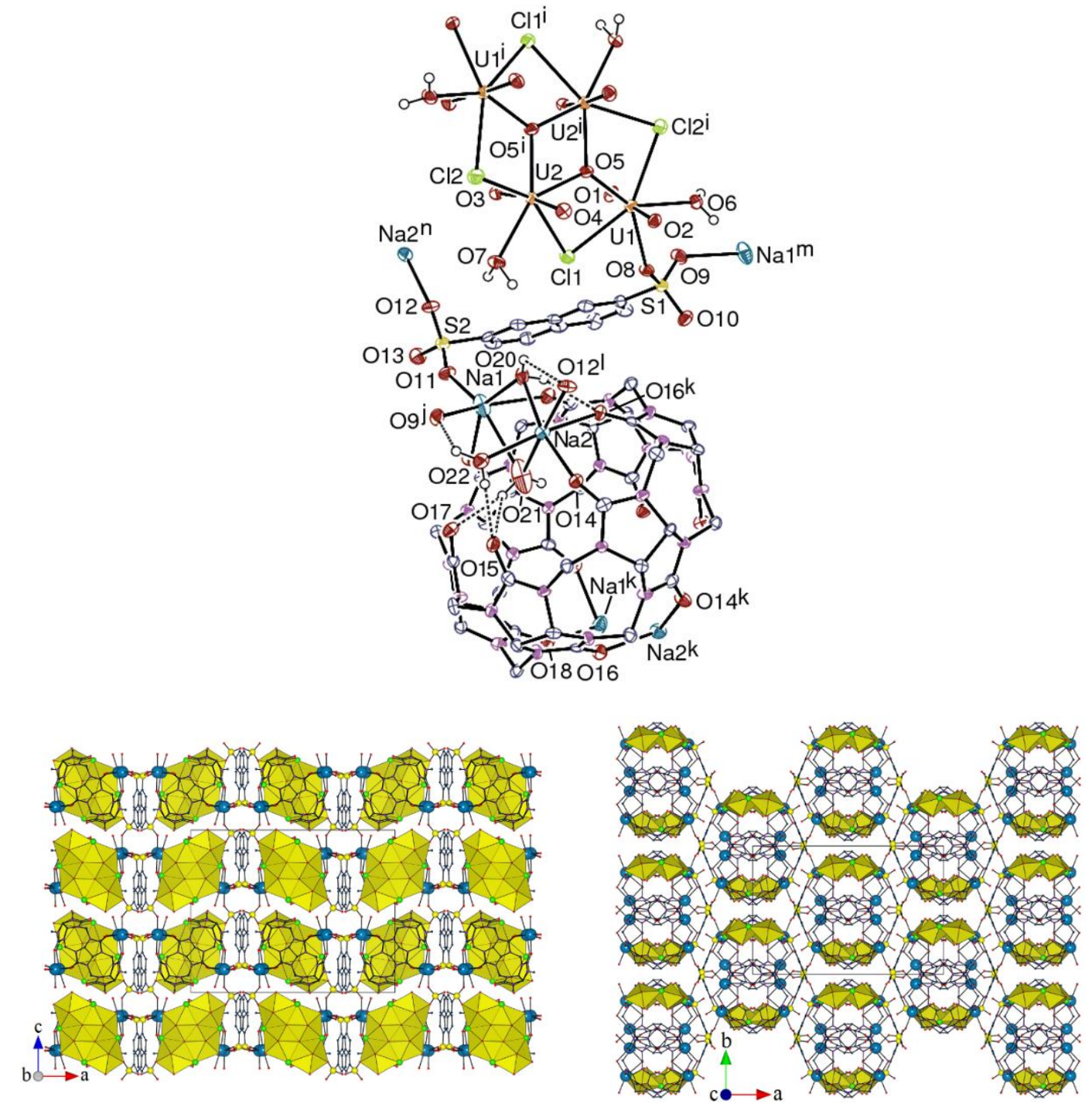

Figure 6. Top: View of complex 6. Displacement ellipsoids are drawn at the $50 \%$ probability level. The solvent molecules and carbon-bound hydrogen atoms are omitted, and the hydrogen bonds are shown as dashed lines. Symmetry codes: $\mathrm{i}=2-x, y, 3 / 2-z ; \mathrm{j}=3 / 2-x, 3 / 2-y, z+1 / 2 ; \mathrm{k}=1-x, y, 3 / 2-z ; 1=3 / 2-x, y-1 / 2, z ; \mathrm{m}=3 / 2-$ $x, 3 / 2-y, z-1 / 2 ; \mathrm{n}=3 / 2-x, y+1 / 2, z$. Bottom: Two views of the 3D framework with solvent molecules and hydrogen atoms omitted. Uranyl coordination polyhedra are yellow and sodium(I) cations are shown as blue spheres.

structures reported in the CSD [2.81(2) $\AA$ and $\left.89.55(16)^{\circ}\right]$. The bond length of 2.467(4) $\AA$ between $\mathrm{U} 1$ and the sulfonate atom $\mathrm{O} 8$ is in the upper part of the range measured in the other complexes. The 2,7-nds ${ }^{2-}$ ligand is bound to only one uranium atom, but it also connects three sodium(I) cations 
in such a manner that both sulfonate groups are $O, O^{\prime}$-bridging bidentate. The two independent sodium atoms, both in octahedral environments (very distorted in the case of Na1), are bound to either two (Na1) or one (Na2) sulfonate oxygen atoms [Na-O bond lengths 2.398(6)-2.439(5) $\AA$, average 2.421(17) $\AA$; average value for similar bonds in the CSD 2.41(15) $\mathrm{A}$ ], two adjacent

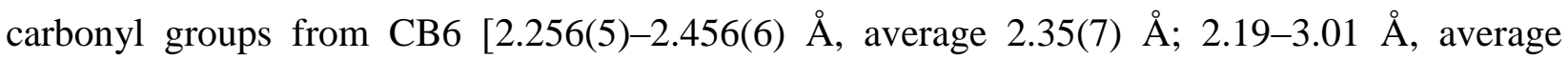
2.49(18) $\AA$ from the CSD], and two (Na1) or three (Na2) water molecules (two of them bridging). One group of two sodium ions is thus held at each CB6 portal, the CB6 molecule having two-fold rotation symmetry. This multi-component, intricate arrangement gives rise to the formation of a 3D framework. When viewed down the $b$ axis, the assembly displays thick layers in which uranyl tetranuclear motifs and CB6 molecules are arranged in staggered rows, separated by thin layers of 2,7-nds ${ }^{2-}$ ligands, all parallel to $\left(\begin{array}{ll}1 & 0\end{array}\right)$. The large number of water molecules, both coordinated and free, results in many hydrogen bonding interactions being present, which involve sulfonate, CB6 and water oxygen acceptors, as well as one chloride ion. Although uranyl ion binding to cucurbiturils has been achieved, ${ }^{[14,22,40-45]}$ it is often reduced to looser associations, either secondsphere or mediated by hydrogen bonds, when alkali or alkaline-earth cations are present, ${ }^{[14,22,43,45]}$ due to the high affinity of cucurbiturils for the latter. In the particular case of the uranyl/alkali cation/sulfonate/CB6 system, several complexes have been obtained which display arrangements different from the present one. Three of the complexes described include either $\mathrm{Na}^{+}$or $\mathrm{K}^{+}$and 4,5dihydroxy-1,3-benzenedisulfonate and crystallize as 1D, 2D or 3D coordination polymers, with in all cases the alkali metal cations occupying the CB6 portals, and the disulfonate ligand bridging both cations. ${ }^{22}$ In another series, uranyl dimers formed with 2-sulfobenzoate are either hydrogen bonded to discrete $\mathrm{Na}(\mathrm{CB} 6)\left(\mathrm{H}_{2} \mathrm{O}\right)_{4}{ }^{+}$moieties, or generate a $1 \mathrm{D}$ polymer through water-bridging to CB6-bound cesium cations; in contrast, 3-sulfobenzoate acts as a bridge between uranium and CB6-bound cesium cations, thus allowing the formation of a 3D framework. ${ }^{[14]}$ These and the 
present results would indicate that disulfonate or carboxysulfonate ligands unable to chelate uranyl through both their functional groups would offer a better prospect for the formation of 3D lattices, but this is not always verified since, although 4-sulfobenzoate is able to bridge uranyl and potassium ions, a discrete heterometallic species only is formed in this case. ${ }^{[14]}$

\section{Luminescence Properties}

The emission spectra of complexes $\mathbf{2 - 5}$ in the solid state were recorded at room temperature under excitation at a wavelength of $420 \mathrm{~nm}$, a value suitable for excitation of the uranyl chromophore, ${ }^{[46]}$ and they are shown in Figure 7. Only in the cases of complexes $\mathbf{2}$ and $\mathbf{4}$ are intense and well-resolved spectra obtained showing the typical vibronic progression corresponding to the $S_{11} \rightarrow S_{00}$ and $S_{10} \rightarrow S_{0 v}(v=0-4)$ electronic transitions. ${ }^{[47]}$ The spectrum of complex 2 , with main maxima at 495, 518, 542 and $568 \mathrm{~nm}$ is blue-shifted by $8 \mathrm{~nm}$ with respect to that of complex 4 , with maxima at 503, 526, 550 and $576 \mathrm{~nm}$, although the uranyl ion environment is nearly the same in both compounds. The lower resolution in the spectrum of $\mathbf{4}$ may be a reflection of the superposition of more than one vibronic progression associated with the unique uranyl centre in the lattice. In simpler systems, multiple progressions for single centres have been resolved in lowtemperature measurements. ${ }^{[48]}$ Uranyl emission in complexes $\mathbf{3}$ and $\mathbf{5}$ is largely quenched, which is less surprising in the latter case since the presence of d-block metal cations is known to have such an effect, probably through providing nonradiative relaxation pathways. ${ }^{[49]}$ The maxima positions in complex $3,502,524,547$ and $\sim 574 \mathrm{~nm}$, are close to those in complex 4 , but here the 

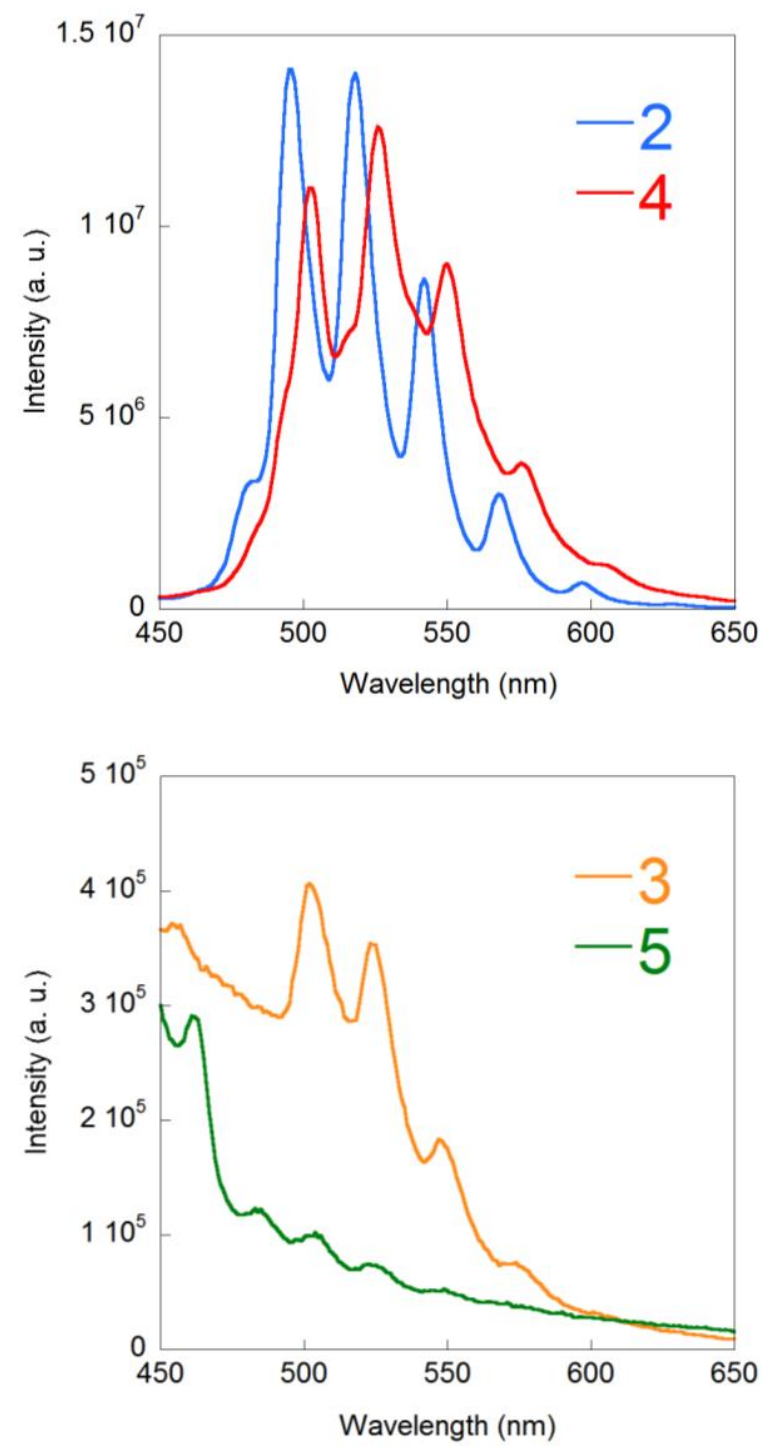

Figure 7. Solid state emission spectra of complexes 2-5. Excitation wavelength $420 \mathrm{~nm}$.

peaks are weak and appear to be superimposed on a broader emission which may be due to the free bipy molecule, indicating that there may be two pathways for deactivation of the excited state produced by irradiation at $420 \mathrm{~nm}$. The discernible maxima for compound $\mathbf{5}$ are at approximate values of 483, 504 and $522 \mathrm{~nm}$ and thus appear strongly blue-shifted with respect to those in the other complexes, although uranium environment is here also pentagonal bipyramidal (but with an equatorial array closer to planarity). While the maxima positions in uranyl emission spectra are 
known to be dependent on the number and nature of equatorial donors, ${ }^{[50,51]}$ subtle factors are nevertheless obviously at play here since significant shifts are observed even in a series of closely related species. The average vibronic splitting energies for the $S_{10} \rightarrow S_{0 v}$ transitions are in the range $821-897 \mathrm{~cm}^{-1}$ for complexes 2 and $\mathbf{4}$, these values being in the range usually observed. ${ }^{[48,52-56]}$

\section{Conclusions}

We have described six novel complexes formed by the uranyl ion with two sulfonate ligands, 1,5- and 2,7-naphthalenedisulfonates. Although the complexing properties of this family of positional isomers of naphthalenedisulfonate ligands toward lanthanide(III) cations have been investigated, ${ }^{[57-59]}$ the present results are the first to involve an actinide cation. The solvothermal syntheses conducted in the present work, despite being designed with the objective of obtaining mixed uranyl/metal ion species, provided such complexes in only two of the six cases where crystals were obtained and in only one case (complex 6) was the sulfonate ligand involved in bridging the two metal ions. While what is seen in the solid state may bear no relationship to what takes place in solution, these results are consistent with broader indications that sulfonate coordination is more favourable for uranyl ion than, in particular, transition metal ions. The fact that the sodium arenesulfonates used in the present work are the conjugate bases of relatively strong acids means that they have little influence on the basicity of their aqueous solutions and this is consistent with the observation that only in the presence of an additional base (bipy or phen) was there evidence for uranyl ion hydrolysis in the products presently characterized. Since, in addition, these sodium salts are quite water-soluble, advantages to the use of solvothermal methods for the synthesis of their uranyl complexes are less obvious than in the case, for example, of 
polycarboxylates, where hydrolysis can only be minimised by the use of the water-insoluble acids and a mixed organic-aqueous solvent is preferable to pure water.

In the whole series of complexes reported here, the sulfonate groups are bound to either one or two cations (uranyl, sodium, or a mixture thereof in the latter case), and three-fold $O, O^{\prime}, O^{\prime \prime}-$ coordination is never observed, although it is known with 1,5- and 2,6-naphthalenedisulfonates in the case of lanthanide cations, ${ }^{[58,59]}$ and also with the simple methanesulfonate ligand in the case of the uranyl cation. ${ }^{[18]}$ 1,5-Naphthalenedisulfonate appears suitable for the building of a 3D framework with uranyl, as exemplified in the stoichiometrically simplest complex obtained (1), in which both metal and ligand are four-fold nodes. The lattice in $\mathbf{1}$ does have a layered form, with the layers "pillared" by naphthalene units apparently too close to permit guest intrusion in the pillared regions, despite the fact that the naphthalene units do not seem to be involved in significant interactions with one another. Addition of a chelating $N$-donor, bipy or phen, and the concomitant presence of double hydroxide bridges (possibly due to the increased basicity of the reaction medium), reduce the dimensionality and 1D coordination polymers are formed, in which each sulfonate group is unidentate (complexes 2-4). In the presence of copper(II) as counter-ion, 2,7naphthalenedisulfonate adopts a mixed unidentate $/ O, O^{\prime}$-bridging coordination mode which unites double-hydroxide-bridged uranyl dimers into a 2D network (complex 5). Finally, a second 3D framework, of intricate architecture, is generated with 2,7-naphthalenedisulfonate in the presence of cucurbit[6]uril and $\mathrm{Na}^{+}$cations, in which the sulfonate groups bridge either one uranium and one sodium, or two sodium cations (complex 6). These results provide novel examples of the use of sulfonates, much less investigated than phosphonates in uranyl chemistry, to generate 3D architectures, although none of those reported displays significant porosity. 


\section{Experimental Section}

General: $\mathrm{UO}_{2}\left(\mathrm{NO}_{3}\right)_{2} \cdot 6 \mathrm{H}_{2} \mathrm{O}$ (depleted uranium, R. P. Normapur, 99\%), $\mathrm{Ni}\left(\mathrm{NO}_{3}\right)_{2} \cdot 6 \mathrm{H}_{2} \mathrm{O}$ and $\mathrm{AgNO}_{3}$ were purchased from Prolabo, the di-sodium salt of 2,7-naphthalenedisulfonic acid (2,7ndsNa2), cucurbit[6]uril pentahydrate, and 2,2'-bipyridine (bipy) were from Fluka, $\mathrm{Cu}\left(\mathrm{NO}_{3}\right)_{2} \cdot 2.5 \mathrm{H}_{2} \mathrm{O}$, the di-sodium salt of 1,5-naphthalenedisulfonic acid (1,5-ndsNa $)$ and 1,10 phenanthroline (phen) were from Aldrich. Elemental analyses were performed by MEDAC Ltd. at Chobham, UK.

Caution! Uranium is a radioactive and chemically toxic element, and uranium-containing samples must be handled with suitable care and protection.

[UO-2 (1,5-nds)(H2O)] (1): 1,5-ndsNa 2 (17 mg, $0.05 \mathrm{mmol}), \mathrm{UO}_{2}\left(\mathrm{NO}_{3}\right)_{2} \cdot 6 \mathrm{H}_{2} \mathrm{O}(25 \mathrm{mg}, 0.05 \mathrm{mmol})$, 18-crown-6 (26 mg, $0.10 \mathrm{mmol})$, and demineralized water $(0.5 \mathrm{~mL})$ were placed in a $15 \mathrm{~mL}$ tightly closed glass vessel and heated at $140{ }^{\circ} \mathrm{C}$ under autogenous pressure, giving light yellow crystals of complex 1 in low yield within two weeks.

$\left[\left(\mathbf{U O}_{2}\right)_{2}(\mathbf{1 , 5}-\mathbf{n d s})(\mathbf{O H})_{2}(\mathbf{b i p y})_{2}\right] \cdot \mathrm{H}_{2} \mathrm{O}$ (2): $1,5-\mathrm{ndsNa}_{2}(17 \mathrm{mg}, 0.05 \mathrm{mmol}), \mathrm{UO}_{2}\left(\mathrm{NO}_{3}\right)_{2} \cdot 6 \mathrm{H}_{2} \mathrm{O}(25$ $\mathrm{mg}, 0.05 \mathrm{mmol}), \mathrm{Mn}\left(\mathrm{NO}_{3}\right)_{2} \cdot 4 \mathrm{H}_{2} \mathrm{O}$ (13 mg, $\left.0.05 \mathrm{mmol}\right), 2,2^{\prime}$-bipyridine (16 mg, $\left.0.10 \mathrm{mmol}\right)$, and demineralized water $(0.8 \mathrm{~mL})$ were placed in a $15 \mathrm{~mL}$ tightly closed glass vessel and heated at 140 ${ }^{\circ} \mathrm{C}$ under autogenous pressure, giving light yellow crystals of complex 2 in low yield within two weeks.

[(UO $\left.)_{2}\right)_{2}(\mathbf{1 , 5}-\mathbf{n d s})(\mathbf{O H})_{2}(\text { bipy) })_{2} \cdot$ bipy (3): 1,5-ndsNa $(17 \mathrm{mg}, 0.05 \mathrm{mmol}), \mathrm{UO}_{2}\left(\mathrm{NO}_{3}\right)_{2} \cdot 6 \mathrm{H}_{2} \mathrm{O}(25$ $\mathrm{mg}, 0.05 \mathrm{mmol}), \mathrm{Ni}\left(\mathrm{NO}_{3}\right)_{2} \cdot 6 \mathrm{H}_{2} \mathrm{O}(15 \mathrm{mg}, 0.05 \mathrm{mmol}), 2,2^{\prime}$-bipyridine (24 mg, $\left.0.15 \mathrm{mmol}\right)$, acetonitrile $(0.2 \mathrm{~mL})$, and demineralized water $(0.7 \mathrm{~mL})$ were placed in a $15 \mathrm{~mL}$ tightly closed glass vessel and heated at $140{ }^{\circ} \mathrm{C}$ under autogenous pressure, giving light yellow crystals of complex $\mathbf{3}$ in low yield within one week. 
[(UO) $)_{2}$ (1,5-nds)(OH)2(phen) $)_{2}$ (4): 1,5-ndsNa $2(17 \mathrm{mg}, 0.05 \mathrm{mmol}), \mathrm{UO}_{2}\left(\mathrm{NO}_{3}\right)_{2} \cdot 6 \mathrm{H}_{2} \mathrm{O}(25 \mathrm{mg}$, $0.05 \mathrm{mmol}), \mathrm{Pb}\left(\mathrm{NO}_{3}\right)_{2}(17 \mathrm{mg}, 0.05 \mathrm{mmol}), 1,10$-phenanthroline (18 mg, $\left.0.10 \mathrm{mmol}\right), N$-methyl2-pyrrolidone $(0.2 \mathrm{~mL})$, and demineralized water $(0.7 \mathrm{~mL})$ were placed in a $15 \mathrm{~mL}$ tightly closed glass vessel and heated at $140{ }^{\circ} \mathrm{C}$ under autogenous pressure, giving light yellow crystals of complex 4 in low yield within one week.

$\left[\mathbf{C u}(\text { bipy) })_{2} \mathbf{C l}\right]\left[\mathbf{U O}_{2}\left(\mathbf{2 , 7}\right.\right.$-nds)(OH)] $\cdot \mathbf{H}_{2} \mathrm{O}$ (5): 2,7-ndsNa 2 (17 mg, $\left.0.05 \mathrm{mmol}\right), \mathrm{UO}_{2}\left(\mathrm{NO}_{3}\right)_{2} \cdot 6 \mathrm{H}_{2} \mathrm{O}$ (25 mg, $0.05 \mathrm{mmol}), \mathrm{Cu}\left(\mathrm{NO}_{3}\right)_{2} \cdot 2.5 \mathrm{H}_{2} \mathrm{O}$ (12 mg, $\left.0.05 \mathrm{mmol}\right), 2,2^{\prime}$-bipyridine (16 mg, $0.10 \mathrm{mmol}$ ), and demineralized water $(0.7 \mathrm{~mL})$ were placed in a $15 \mathrm{~mL}$ tightly closed glass vessel and heated at $140{ }^{\circ} \mathrm{C}$ under autogenous pressure, giving light green crystals of complex 5 within one week (11 mg, 22\% yield). $\mathrm{C}_{30} \mathrm{H}_{25} \mathrm{ClCuN}_{4} \mathrm{O}_{10} \mathrm{~S}_{2} \mathrm{U}$ (1002.68): calcd. C 35.94, H 2.51, N 5.59; found C 35.89, H 2.68, N 5.71.

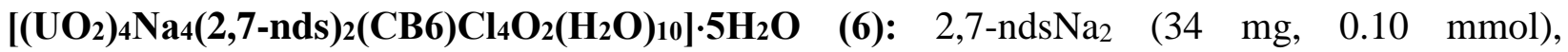
$\mathrm{UO}_{2}\left(\mathrm{NO}_{3}\right)_{2} \cdot 6 \mathrm{H}_{2} \mathrm{O}(50 \mathrm{mg}, 0.10 \mathrm{mmol}), \mathrm{CB} 6 \cdot 5 \mathrm{H}_{2} \mathrm{O}(11 \mathrm{mg}, 0.01 \mathrm{mmol})$, and demineralized water $(1.0 \mathrm{~mL})$ were placed in a $15 \mathrm{~mL}$ tightly closed glass vessel and heated at $180^{\circ} \mathrm{C}$ under autogenous pressure, giving light yellow crystals of complex $\mathbf{6}$ in low yield within two weeks.

Crystallography: The data were collected at 150(2) K on a Nonius Kappa-CCD area detector diffractometer ${ }^{[60]}$ using graphite-monochromated Mo Ka radiation $(\lambda=0.71073 \AA)$. The crystals were introduced into glass capillaries with a protective coating of Paratone-N oil (Hampton Research). The unit cell parameters were determined from ten frames, then refined on all data. The data (combinations of $\varphi$ - and $\omega$-scans with a minimum redundancy of 4 for $90 \%$ of the reflections) were processed with HKL2000. ${ }^{[61]}$ Absorption effects were corrected empirically with the program SCALEPACK.${ }^{[61]}$ The structures were solved by intrinsic phasing with SHELXT, ${ }^{[62]}$ expanded by 
subsequent difference Fourier synthesis and refined by full-matrix least-squares on $F^{2}$ with SHELXL-2014. ${ }^{[63]}$ All non-hydrogen atoms were refined with anisotropic displacement parameters. The hydrogen atoms bound to hydroxyl and water oxygen atoms were found on difference Fourier maps (except for those of a disordered water molecule in complex 6), and the carbon-bound hydrogen atoms were introduced at calculated positions; all hydrogen atoms were treated as riding atoms with an isotropic displacement parameter equal to 1.2 times that of the parent atom. Crystal data and structure refinement parameters are given in Table 1. The molecular plots were drawn with ORTEP-3 ${ }^{[64]}$ and the polyhedral representations with VESTA. ${ }^{[65]}$ The topological analyses were made with TOPOS. ${ }^{[66]}$

CCDC-1515430-1515435 contain the supplementary crystallographic data for this paper. These data can be obtained free of charge from The Cambridge Crystallographic Data Centre via www.ccdc.cam.ac.uk/data_request/cif.

Table 1 Crystal data and structure refinement details

\begin{tabular}{|c|c|c|c|c|c|c|}
\hline & 1 & 2 & 3 & 4 & 5 & 6 \\
\hline Empirical formula & $\mathrm{C}_{10} \mathrm{H}_{8} \mathrm{O}_{9} \mathrm{~S}_{2} \mathrm{U}$ & $\mathrm{C}_{30} \mathrm{H}_{26} \mathrm{~N}_{4} \mathrm{O}_{13} \mathrm{~S}_{2} \mathrm{U}_{2}$ & $\mathrm{C}_{40} \mathrm{H}_{32} \mathrm{~N}_{6} \mathrm{O}_{12} \mathrm{~S}_{2} \mathrm{U}_{2}$ & $\mathrm{C}_{34} \mathrm{H}_{24} \mathrm{~N}_{4} \mathrm{O}_{12} \mathrm{~S}_{2} \mathrm{U}_{2}$ & $\mathrm{C}_{30} \mathrm{H}_{25} \mathrm{ClCuN}_{4} \mathrm{O}_{10} \mathrm{~S}_{2} \mathrm{U}$ & $\mathrm{C}_{56} \mathrm{H}_{78} \mathrm{Cl}_{4} \mathrm{~N}_{24} \mathrm{Na}_{4} \mathrm{O}_{49} \mathrm{~S}_{4} \mathrm{U}_{4}$ \\
\hline $\mathrm{M} / \mathrm{g} \mathrm{mol}^{-1}$ & 574.31 & 1190.73 & 1328.89 & 1220.75 & 1002.68 & 3185.54 \\
\hline Crystal system & Orthorhombic & Triclinic & Monoclinic & Triclinic & Triclinic & Orthorhombic \\
\hline Space group & Pbcn & $P_{1}$ & $P 2_{1} / n$ & $P_{1}$ & $P_{1}$ & Pbcn \\
\hline$a / \AA$ & $8.3036(5)$ & $9.9948(5)$ & $10.7903(5)$ & $8.4226(5)$ & $8.9368(3)$ & $25.7129(10)$ \\
\hline$b / \AA ̊$ & $8.1107(3)$ & $11.9666(8)$ & $13.3237(7)$ & $9.5647(6)$ & $13.1629(7)$ & $17.2549(4)$ \\
\hline$c / \AA$ & $19.4518(10)$ & $14.2331(9)$ & $14.4850(6)$ & $11.1317(10)$ & $14.0127(7)$ & $20.4342(8)$ \\
\hline$\alpha /^{\circ}$ & 90 & $73.879(3)$ & 90 & $106.763(4)$ & $95.343(2)$ & 90 \\
\hline$\beta /^{\circ}$ & 90 & $89.140(4)$ & $99.684(3)$ & $97.503(5)$ & $93.436(3)$ & 90 \\
\hline$y^{\circ}$ & 90 & $85.100(4)$ & 90 & $98.967(4)$ & $91.245(3)$ & 90 \\
\hline$V / \AA^{3}$ & $1310.04(11)$ & $1629.35(17)$ & $2052.79(17)$ & $833.43(11)$ & $1637.64(13)$ & $9066.1(5)$ \\
\hline Z & 4 & 2 & 2 & 1 & 2 & 4 \\
\hline$\rho_{\text {calcd }} / \mathrm{g} \mathrm{cm}^{-3}$ & 2.912 & 2.427 & 2.150 & 2.432 & 2.033 & 2.334 \\
\hline$\mu\left(\mathrm{Mo}-\mathrm{K}_{\alpha}\right) / \mathrm{mm}^{-1}$ & 12.756 & 10.130 & 8.053 & 9.903 & 5.860 & 7.468 \\
\hline$F(000)$ & 1056 & 1108 & 1252 & 568 & 966 & 6072 \\
\hline Reflections collected & 30519 & 88499 & 69485 & 35254 & 82945 & 184947 \\
\hline Independent reflections & 1688 & 6194 & 6251 & 3162 & 8446 & 8585 \\
\hline Observed reflections $[I>2 \sigma(I)]$ & 1385 & 5122 & 5113 & 2901 & 7447 & 6017 \\
\hline$R_{\text {int }}$ & 0.015 & 0.064 & 0.037 & 0.054 & 0.043 & 0.047 \\
\hline Parameters refined & 101 & 460 & 280 & 244 & 442 & 658 \\
\hline$R_{1}$ & 0.023 & 0.029 & 0.029 & 0.027 & 0.027 & 0.039 \\
\hline $\mathrm{w} R_{2}$ & 0.056 & 0.065 & 0.068 & 0.066 & 0.061 & 0.082 \\
\hline$S$ & 1.100 & 1.028 & 0.991 & 1.081 & 1.022 & 1.003 \\
\hline$\Delta \rho_{\min } / \mathrm{e} \AA^{-3}$ & -1.29 & -1.63 & -1.80 & -2.33 & -1.67 & -1.09 \\
\hline$\Delta \rho_{\max } / \mathrm{e} \AA^{-3}$ & 0.62 & 2.51 & 0.86 & 0.94 & 0.64 & 1.11 \\
\hline
\end{tabular}


Luminescence measurements: Emission spectra were recorded on solid samples using a HoribaJobin-Yvon Fluorolog spectrofluorometer. The powdered complex was pressed between two silica plates which were mounted such that the faces were oriented vertically and at $45^{\circ}$ to the incident excitation radiation. An excitation wavelength of $420 \mathrm{~nm}$ was used in all cases and the emissions monitored between 450 and $650 \mathrm{~nm}$.

\section{References}

[1] A. P. Côté, G. K. H. Shimizu, Coord. Chem. Rev. 2003, 245, 49-64.

[2] J. Cai, Coord. Chem. Rev. 2004, 248, 1061-1083.

[3] V. Videnova-Adrabinska, Coord. Chem. Rev. 2007, 251, 1987-2016.

[4] G. K. H. Shimizu, R. Vaidhayanathan, J. M. Taylor, Chem. Soc. Rev. 2009, 38, 1430-1449.

[5] G. A. Lawrance, Adv. Inorg. Chem. 1989, 34, 145-194.

[6] K. T. Holman, A. M. Pivovar, J. A. Swift, M. D. Ward, Acc. Chem. Res. 2001, 34, 107118.

[7] D. M. Faithfull, J. M. Harrowfield, M. I. Ogden, B. W. Skelton, K. Third, A. H. White, Aust. J. Chem. 1992, 45, 583-594.

[8] P. Thuéry, CrystEngComm 2012, 14, 6369-6373.

[9] S. Shinkai, H. Koreishi, K. Ueda, T. Arimura, O. Manabe, J. Am. Chem. Soc. 1987, 109, $6371-6376$.

[10] G. Montavon, U. Repinc, C. Apostolidis, F. Bruchertseifer, K. Abbas, A. Morgenstern, Dalton Trans. 2010, 39, 1366-1374.

[11] K. Kiegiel, L. Steczek, G. Zakrzewska-Trznadel, J. Chem. 2013, Article ID 762819 (16 pp.), DOI org/10.1155/2013/762819. 
[12] P. Thuéry, CrystEngComm 2012, 14, 3363-3366.

[13] P. Thuéry, Eur. J. Inorg. Chem. 2014, 58-68.

[14] P. Thuéry, Cryst. Growth Des. 2011, 11, 5702-5711.

[15] A. S. Wilson, Acta Cryst. 1978, B34, 2302-2303.

[16] N. W. Alcock, T. J. Kemp, J. Leciejewicz, Inorg. Chim. Acta 1993, 203, 81-86.

[17] G. B. Andreev, N. A. Budantseva, I. G. Tananaev, B. F. Myasoedov, Acta Cryst. 2007, E63, $\mathrm{m} 3159$.

[18] U. Betke, K. Neuschulz, M. S. Wickleder, Chem. Eur. J. 2011, 17, 12784-12801.

[19] C. R. Groom, I. J. Bruno, M. P. Lightfoot, S. C. Ward, Acta Crystallogr., Sect. B 2016, 72, $171-179$.

[20] P. A. Smith, P. C. Burns, CrystEngComm 2014, 16, 7244-7250.

[21] Y. Zhang, J. R. Price, I. Karatchevtseva, K. Lu, B. Yoon, F. Kadi, G. R. Lumpkin, F. Li, Polyhedron 2015, 91, 98-103.

[22] P. Thuéry, Cryst. Growth Des. 2011, 11, 3282-3294.

[23] R. Solhnejad, F. N. Bahmanova, A. M. Maharramov, R. A. Aliyeva, F. M. Chyragov, A. V. Gurbanov, G. S. Mahmudova, K. T. Mahmudov, M. N. Kopylovich, Inorg. Chem. Comm. 2013, 35, 13-15.

[24] P. Thuéry, Inorg. Chem. 2013, 52, 435-447.

[25] P. Thuéry, CrystEngComm 2013, 15, 2401-2410.

[26] W. Yang, T. Tian, H. Y. Wu, Q. J. Pan, S. Dang, Z. M. Sun, Inorg. Chem. 2013, 52, 27362743.

[27] M. B. Andrews, C. L. Cahill, Chem. Rev. 2013, 113, 1121-1136.

[28] T. Loiseau, I. Mihalcea, N. Henry, C. Volkringer, Coord. Chem. Rev. 2014, 266-267, 69109. 
[29] J. Su, J. S. Chen, Struct. Bond. 2015, 163, 265-296.

[30] M. A. Spackman, D. Jayatilaka, CrystEngComm 2009, 11, 19-32.

[31] S. K. Wolff, D. J. Grimwood, J. J. McKinnon, M. J. Turner, D. Jayatilaka, M. A. Spackman, CrystalExplorer, University of Western Australia, 2012.

[32] A. L. Spek, Acta Crystallogr., Sect. D 2009, 65, 148-155.

[33] P. Thuéry, J. Harrowfield, CrystEngComm 2016, 18, 3905-3918, and references therein.

[34] R. Taylor, O. Kennard, J. Am. Chem. Soc. 1982, 104, 5063-5070.

[35] G. R. Desiraju, Acc. Chem. Res. 1996, 29, 441-449.

[36] A. Gavezzotti, CrystEngComm 2013, 15, 4027-4035.

[37] G. Van den Bossche, M. R. Spirlet, J. Rebizant, J. Goffart, Acta Crystallogr., Sect. C 1987, $43,837-839$.

[38] O. A. Gerasko, D. G. Samsonenko, A. A. Sharonova, A. V. Virovets, J. Lipkowski, V. P. Fedin, Russ. Chem. Bull., Int. Ed. 2002, 51, 346-349.

[39] C. Hennig, K. Servaes, P. Nockemann, K. Van Hecke, L. Van Meervelt, J. Wouters, L. Fluyt, C. Görller-Walrand, R. Van Deun, Inorg. Chem. 2008, 47, 2987-2993.

[40] P. Thuéry, Cryst. Growth Des. 2008, 8, 4132-4143.

[41] P. Thuéry, Inorg. Chem. 2009, 48, 825-827.

[42] P. Thuéry, CrystEngComm 2009, 11, 1150-1156.

[43] P. Thuéry, Cryst. Growth Des. 2009, 9, 1208-1215.

[44] P. Thuéry, B. Masci, Cryst. Growth Des. 2010, 10, 716-725.

[45] P. Thuéry, Cryst. Growth Des. 2011, 11, 2606-2620.

[46] K. E. Knope, D. T. de Lill, C. E. Rowland, P. M. Cantos, A. de Bettencourt-Dias, C. L. Cahill, Inorg. Chem. 2012, 51, 201-206.

[47] A. Brachmann, G. Geipel, G. Bernhard, H. Nitsche, Radiochim. Acta 2002, 90, 147-153. 
[48] R. G. Surbella, III, M. B. Andrews, C. L. Cahill, J. Solid State Chem. 2016, 236, 257-271.

[49] A. T. Kerr, C. L. Cahill, Cryst. Growth Des. 2014, 14, 1914-1921.

[50] M. P. Redmond, S. M. Cornet, S. D. Woodall, D. Whittaker, D. Collison, M. Helliwell, L. S. Natrajan, Dalton Trans. 2011, 40, 3914-3926.

[51] K. P. Carter, M. Kalaj, C. L. Cahill, Eur. J. Inorg. Chem. 2016, 126-137.

[52] P. Thuéry, J. Harrowfield, Cryst. Growth Des. 2014, 14, 1314-1323.

[53] P. Thuéry, J. Harrowfield, CrystEngComm 2016, 18, 1550-1562.

[54] P. Thuéry, E. Rivière, J. Harrowfield, Cryst. Growth Des. 2016, 16, 2826-2835.

[55] N. P. Martin, C. Falaise, C. Volkringer, N. Henry, P. Farger, C. Falk, E. Delahaye, P. Rabu, T. Loiseau, Inorg. Chem. 2016, 55, 8697-8705.

[56] P. Thuéry, J. Harrowfield, Cryst. Growth Des. DOI: 10.1021/acs.cgd.6b01312.

[57] R. Li, X. L.Qu, Y. H. Zhang, H. L. Han, X. Li, CrystEngComm 2016, 18, 5890-5900, and references therein.

[58] N. Snejko, C. Cascales, B. Gomez-Lor, E. Gutiérrez-Puebla, M. Iglesias, C. Ruiz-Valero, M. A. Monge, Chem. Commun. 2002, 1366-1367.

[59] F. Gándara, A. García-Cortés, C. Cascales, B. Gómez-Lor, E. Gutiérrez-Puebla, M. Iglesias, A. Monge, N. Snejko, Inorg. Chem. 2007, 46, 3475-3484.

[60] R. W. W. Hooft, COLLECT, Nonius BV: Delft, The Netherlands, 1998.

[61] Z. Otwinowski, W. Minor, Methods Enzymol. 1997, 276, 307-326.

[62] G. M. Sheldrick, Acta Crystallogr., Sect. A 2015, 71, 3-8.

[63] G. M. Sheldrick, Acta Crystallogr., Sect. C 2015, 71, 3-8.

[64] L. J. Farrugia, J. Appl. Crystallogr. 1997, 30, p. 565.

[65] K. Momma, F. Izumi, J. Appl. Crystallogr. 2008, 41, 653-658.

[66] V. A. Blatov, TOPOS, Samara State University, Russia, 2004. 


\title{
Table of Contents Entry
}

\section{Complexation of Uranyl Ion with Sulfonates: One- to Three-Dimensional Assemblies with 1,5- and 2,7-Naphthalenedisulfonates}

\author{
Pierre Thuéry and Jack Harrowfield
}

Key Topic: Uranyl disulfonate complexes

\begin{abstract}
Although less studied than phosphonates in uranyl chemistry, sulfonates are versatile ligands, as evidenced by six new complexes obtained with 1,5- or 2,7-naphthalenedisulfonates, which crystallize as one- to three-dimensional species. While terminating $N$-chelating ligands reduce the dimensionality, frameworks are generated when the disulfonate is coordinated in a doubly $O, O^{\prime}-$ bridging mode.
\end{abstract}

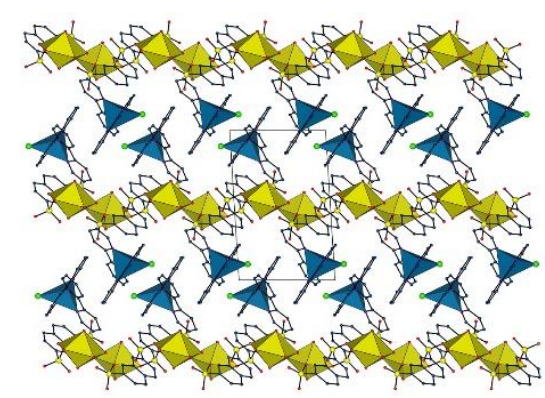

